No dia 17 de junho, a convite da Faculdade, fez o professor Fischel, na sala "João Mendes Junior", uma conferência sobre "A renascença econômica e espiritual da Pérsia".

A sessão foi presidida pelo professor Spencer Vampré, diretor da Faculdade de Direito.

\title{
BIBLIOTECA DA FACULDADE DE DIREITO
}

Frequência no primeiro semestre de 1938

Aumentou, no primeiro semestre do corrente ano, a frequência de estudantes e consulentes na Biblioteca da Faculdade de Direito. De acôrdo com a estatistica levantada pela Chefia 'T'écnica, o movimento foi de 43.526 pessoas, assim computadas:

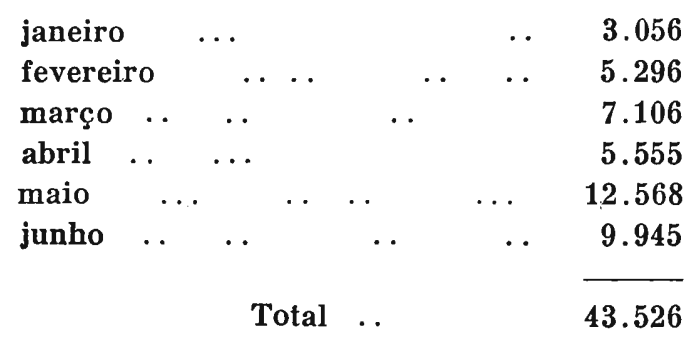

\section{A R. UNIVERSITA DI ROMA E A FACULDADE DE DIREITO DE SÃO PAULO}

Carta do professor Giorgio Del Vecchio em resposta à mensagem que lhe foi enviada

No fasciculo anterior, publicou a "Revista da Faculdade de Direito de S. Paulo" a mensagem do antigo diretor professor Francisco Morato ao professor Giorgio Del Vecchio, diretor da Facoltà di Giurisprudenza da R. Università de Roma. Da mensagem foi portador o professor Jorge Americano, lente da Faculdade, que chefiou a embaixada acadêmica que visitou aquela Universidade em começos do corrente ano. 
Respondendo á mensagem, assim se expressou o eminente professor italiano:

"Roma, 12 Marzo 1938.

\section{Eccellentissimo ed illustre Collega,}

Col piú vivo piacere e con vero sentimento di gratitudine ho ricevuto il cortese messagio che a V. E. é piaciuto d'inviarmi a mezzo del chiarissimo prof. Jorge Americano, che ha fatto all'Università di Roma, $e$ in particolare a questa Facoltà Giuridica, una visita sommamente gradita: tanto più gradita, in quanto egli era accompagnato da un gruppo di giovani studenti, che rappresentano l'avvenire, certamente glorioso, della nobilissima Nazione brasiliana.

Anche a nome di tutti i miei Colleghi di questa Facoltà, e di tutti gli studenti, assicuro V. E. che i sentimenti di profonda amicizia e di solidarietà latina, espressimi in forma cosi elevata ed eloquente nel messagio di V. E., sono da noi profondamente e cordialmente ricambiati.

Noi conosciamo e seguiamo com ammirazione l'importante sviluppo della scienza giuridica brasiliana, e siamo lieti e orgogliosi che l'insegnamento immortale di Roma sia cosi degnamente proseguito e svolto nel nuovo continente, specialmente per opera di quell'eccelso faro di civiltà latina che è la gloriosa Università di San Paolo del Brasile.

Sono certo che i vincoli di fraternità fra le nostre due Patrie si conserveranno e rafforzeranno sempre più, dando i migliori frutti anche nel campo del diritto, che rappresenta la condizione prima della nostra comune civiltà.

Mentre vivamente ringrazio $\mathrm{I}^{\prime} \mathrm{E}$. $\mathrm{V}$. anche per il conspicuo dono di pregevolissimi libri giuridici, che Ella ha voluto far pervenire a questa Facoltà e che sono stati opportunamente distribuiti tra le Biblioteche dei suoi Instituti, prego l'E. V. di voler accogliere una modesta medaglia ricordo dell'Università di Roma, e alcune publicazioni sulla stessa Università, che col consenso del Magnifico Rettore S. E. De Francisci ho l'onore di spedirle, come segno della nostra simpatia. 


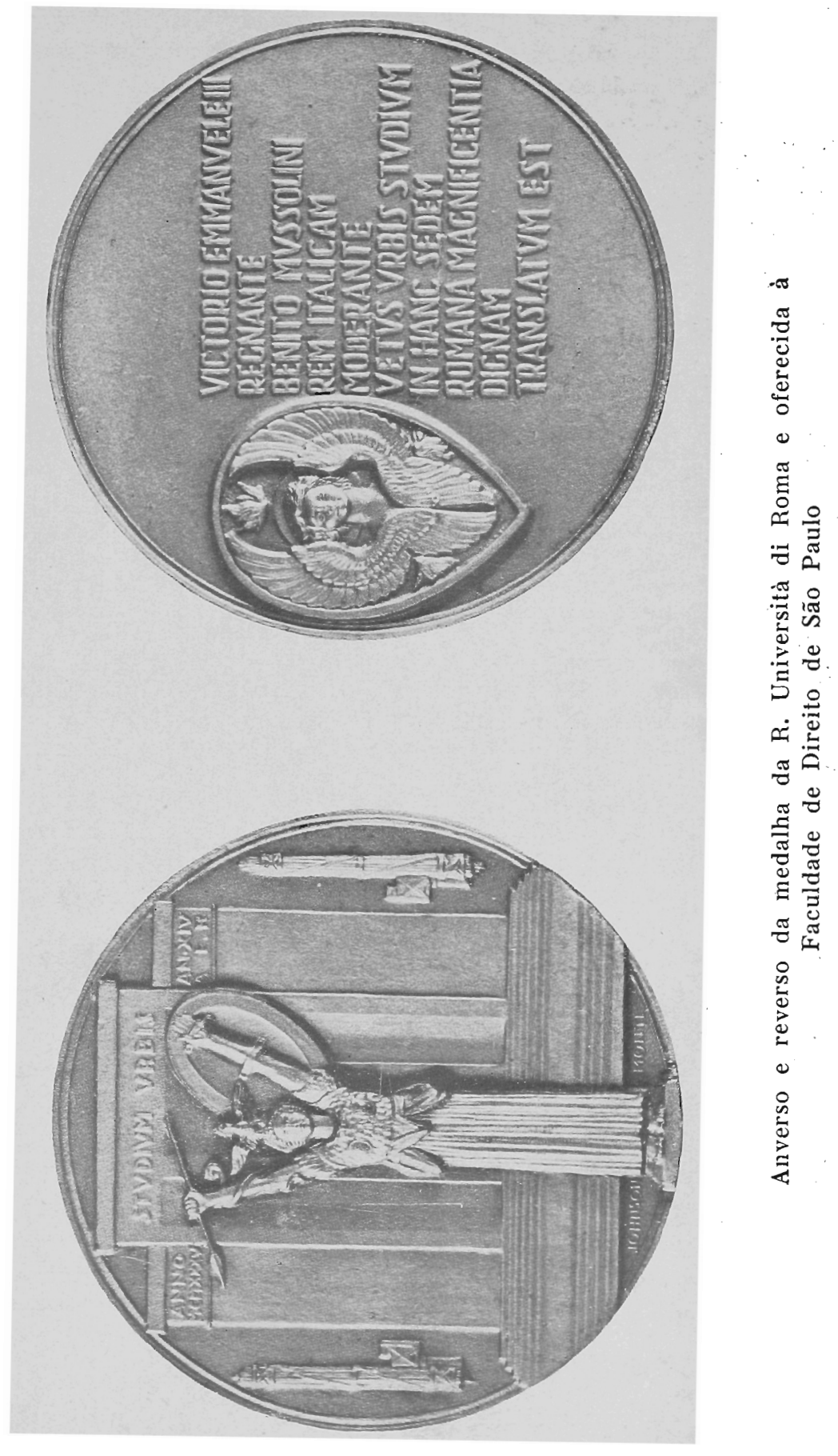


Accolga, Eccellenza, e voglia comunicare alla intiera Facoltà da lei degnamente presieduta, insieme coi miei vivi ringraziamenti, i miei ossequi ed auguri migliori. Di V. E. dev.mo

(a) Grorgio DeL Vecchio

All'Eccellentissimo

Prof. Francisco Morato

Direttore della Facoltà di Diritto di San Paolo".

Damos, à parte, a reprodução fotográfica do anverso e reverso da medalha da $R$. Univeristà di Roma e oferecida à Faculdade de Direito de São Paulo. 